\title{
AS ATIVIDADES DE DESENVOLVIMENTO DE PRODUTOS DE TRÊS MONTADORAS DE MOTORES PARA AUTOMÓVEIS - ESTUDOS DE CASO NO SETOR AUTOMOBILÍSTICO BRASILEIRO
}

\section{PRODUCT DEVELOPMENT ACTIVITIES IN THREE AUTOMOTIVE ENGINE MANUFACTURERS - CASE STUDIES IN THE BRAZILIAN AUTOMOTIVE SECTOR}

\author{
Aline Lamon Cerra ${ }^{1}$; Jonas Lucio Maia ${ }^{2}$ \\ ${ }^{1}$ Universidade Federal de São Carlos - UFSCar - São Carlos - Brasil \\ alinelc@terra.com.br \\ ${ }^{2}$ Universidade Federal de São Carlos - UFSCar - São Carlos - Brasil \\ jonasmaia@dep.ufscar.br
}

\begin{abstract}
Resumo
No Brasil, as atividades de Desenvolvimento de Produtos do setor automobilístico vêm sendo influenciadas por fenômenos especificos ao cenário brasileiro, como os motores de 1000cc e bicombustiveis, bem como por alterações nas cadeias de suprimentos, resultantes da instalação de novas montadoras e da consolidação e desnacionalização do setor de autopeças. Este trabalho tem por objetivo comparar a autonomia concedida à estrutura de Desenvolvimento de Produtos de três montadoras de motores e também o esforço tecnológico delas que é realizado em conjunto com os fornecedores. Os resultados deste estudo demonstraram que essas empresas apresentam autonomia crescente em relação as suas respectivas matrizes no exterior para desenvolverem produtos a partir de outros já existentes, além da autonomia para realizarem inovações em processos de produção. Quando a montadora desenvolve um novo produto, demanda inovações na sua cadeia defornecedores.
\end{abstract}

Palavras-chave: Desenvolvimento de Produtos (DP), Motores para Automóveis, Indústria Automobilística Brasileira.

\section{1 - Introdução}

A capacidade de renovação e de desenvolvimento de produtos tem sido considerada, cada vez mais, elemento de competitividade entre as montadoras automobilísticas. 
Segundo CONSONI (2004), os esforços tecnológicos realizados por subsidiárias de montadoras de automóveis atuantes no Brasil ocorrem essencialmente em Desenvolvimento de Produtos (DP), mas não são despendidos no desenvolvimento da pesquisa tecnológica ou mesmo com o incremento da Pesquisa e Desenvolvimento (P\&D) local.

Assim, a concepção do produto e a elaboração de desenhos de engenharia ficam nas matrizes dessas empresas. Na maioria dos casos, a participação local das subsidiárias refere-se menos a atividades de desenvolvimento stricto sensu e mais a projeto detalhado de aplicações locais. Além disso, as atividades da engenharia brasileira concentram-se em atividades de projeto de processo e não em projeto de produto (SALERNO et al, 2001).

No entanto, é importante ressaltar, segundo ROZENFELD et al (2006), que mesmo que a tecnologia e a concepção de um novo produto venham do exterior, existem ainda muitas atividades de desenvolvimento (do projeto dos produtos locais, passando pelo projeto dos processos, testes, projetos de fábrica, etc), que estão inseridas no escopo de desenvolvimento de produtos, e que fazem parte das responsabilidades de empresas locais.

Este trabalho tem por objetivo comparar a autonomia concedida à estrutura de Desenvolvimento de Produtos de três montadoras de motores para automóveis instaladas no Brasil e também o esforço tecnológico das montadoras estudadas que é realizado em conjunto com o fornecedor.

O esforço tecnológico de uma dada empresa pode ser medido pelo montante de recursos que investe em atividades de P\&D e em capacitação tecnológica (SOBEET, 2000 apud RIEG e ALVES FILHO, 2003). A capacitação tecnológica inclui as despesas com suporte e apoio tecnológico a $\mathrm{P} \& \mathrm{D}$, como registros de marcas e patentes, treinamento de pesquisadores e manutenção de equipamentos usados em P\&D; despesas com aquisição de tecnologias a partir de fontes externas; e despesas com engenharia não-rotineira.

As matrizes das diversas companhias automobilísticas possuem diferentes estratégias de divisão e localização de atividades de desenvolvimento tecnológico e de projeto de produto com relação às suas subsidiárias brasileiras (DIAS, 2003).

No Brasil, com a abertura da economia, a indústria automobilística passou por uma reestruturação importante a partir de 1995, quando diversas montadoras instalaram unidades produtivas em regiões sem tradição no setor automobilístico; neste período, as montadoras de automóveis experimentaram um processo de crescimento e investimento, enquanto que o setor de autopeças atravessava um período de consolidação e desnacionalização (POSTHUMA, 1997).

O aumento da concorrência no mercado brasileiro a partir da década de 90 atraiu investimentos também no segmento de motores para automóveis, especialmente no segmento de baixa cilindrada, para os carros ditos populares. 
As próximas seções tratam da literatura respectivamente a respeito do Desenvolvimento Tecnológico da Indústria Automobilística Brasileira e o Método do trabalho. A seguir, a apresentação e análise dos Estudos de Caso e, finalmente, das Considerações Finais.

\section{2 - Desenvolvimento Tecnológico da Indústria Automobilística Brasileira}

A concepção então predominante era que as subsidiárias mantinham-se totalmente dependentes das suas empresas matrizes quanto ao desenvolvimento de produtos tecnologicamente mais sofisticados e à introdução de processos de produção mais inovadores.

Segundo HUMPREY e SALERNO (2000), houve uma tentativa de padronização do design, porém adaptações locais foram necessárias no Brasil, dada as preferências dos consumidores locais, as diferentes condições das estradas, as características de materiais locais e especificações e custos em relação a regras locais em segurança e poluição. Entretanto, para estes autores, adaptações locais visam, freqüentemente, reduzir custos.

Assim, as capacidades tecnológicas acumuladas nesses países estavam limitadas a esforços localizados de adaptação dos produtos e dos processos de manufatura às condições locais de mercados e insumos, e que se sustentavam a partir da incorporação de tecnologias geradas no exterior (CONSONI, 2004).

Segundo HUMPHREY e SALERNO (2000), novos investimentos em mercados emergentes tornaram-se estratégicos não apenas para montadoras, mas também para os fornecedores de primeiro níveis e subsidiárias de companhias transnacionais. Conseqüentemente, as indústrias automobilísticas destes países têm sido estruturalmente transformadas.

Desde o inicio da década de 90, diversas montadoras instalaram unidades produtivas em regiões sem tradição no setor automobilístico brasileiro.

A partir deste período, estudos sugerem que as subsidiárias de multinacionais localizadas no Brasil não devem ser tratadas como um grupo homogêneo de empresas, cuja atuação nos países hospedeiros segue um único modelo (CONSONI, 2004).

Para DIAS (2003), o processo de desenvolvimento tecnológico (formação de competências) nas empresas subsidiárias depende da conjunção de vários fatores, dentre os quais a estratégia competitiva da empresa e o seu relacionamento com a matriz. Para esta autora, a dispersão das atividades de design em relação às filiais se explica em dois fatores principais:

a) Necessidade de estar próximo ao mercado, para captar as necessidades dos consumidores e aumentar a penetração do produto e de possuir uma capacidade técnica que garanta, no mínimo, a prestação de assistência técnica aos consumidores; 
b) Acesso a "bolsões" de capacidade tecnológica em determinada área (um processo conhecido como technological sourcing), procurando ter acesso aos conhecimentos desenvolvidos e acumulados nestes centros de excelência, estejam eles dentro de uma filial ou fora dela - em centros de pesquisa, universidades, etc, localizados nos países onde está instalada a subsidiária.

A acumulação de capacidades e recursos em uma subsidiária não é um processo necessariamente interligado ou de desenvolvimento concomitante aos demais, pois os recursos são, principalmente, o resultado da acumulação interna de capacidades e, portanto, dependentes da acumulação do desenvolvimento criativo e de suas novas combinações (GOMES, 2003). Além disso, deve-se considerar o tipo de inserção que a subsidiária terá nas estratégias da corporação (CONSONI, 2004).

As montadoras no Brasil apresentam diferentes graus de conhecimento, que se relacionam com estratégias de produtos e de localização de P\&D distintas. Deve-se considerar que as atividades de P\&D realizadas estão orientadas e estruturadas em função dos elementos da competitividade local.

No que se refere à localização das atividades de $\mathrm{P} \& \mathrm{D}$ das empresas automobilísticas que operam no Mercosul, as principais tendências são muito influenciadas pelas distintas estratégias de globalização adotadas pelas montadoras (QUADROS et al, 2000). Segundo os resultados da pesquisa realizada por estes autores, a $G M$ e a Fiat adotaram um enfoque multi-regional de globalização, com maior autonomia concedida a suas divisões regionais ou subsidiária local, e aumentaram suas atividades tecnológicas, especialmente relacionados com o desenvolvimento de produtos, assim como ampliaram seus staffs de engenheiros nos anos recentes. A Ford adotou uma estratégia trans-nacional de globalização e diminuiu o tamanho e a qualidade de suas áreas de P\&D.

A VW, no início de suas operações no Brasil, optou por realizar localmente certas atividades de DP que a princípio eram essencialmente adaptações de produtos, e que ao longo do tempo resultaram em competências técnicas e gerenciais para projetos. Tais atividades diminuíram após a abertura do mercado, porém foram retomadas no início dos anos 2000 (DIAS e SALERNO, 2003).

Durante este mesmo período, novas montadoras surgiram no cenário brasileiro (Renault e PSA, Peugeot Citroen, Toyota, Honda e Daimler Chrysler), centralizando em suas matrizes estrangeiras as atividades de engenharia, sobretudo em relação aos estágios do processo de DP (CONSONI, 2004).

As diversas montadoras instaladas no Brasil modernizaram seus produtos e processos de fabricação e exerceram um papel ativo no processo de atrair fornecedores de seus países de origem. 
Para RACHID (2000), as montadoras ganharam poder tanto em relação aos fornecedores multinacionais como principalmente em relação aos nacionais, pois a presença de capital nacional no setor ficou cada vez mais restrita a pequenas e, no máximo médias empresas, com produtos menos sofisticados e de menor valor agregado, no segundo ou terceiro nível da cadeia de fornecimento. Portanto, nas áreas de maior conteúdo tecnológico, praticamente só permaneceram empresas multinacionais no primeiro nível de fornecimento das montadoras de automóveis.

O processo de reestruturação produtiva nas empresas do setor de autopeças tem ocorrido, em grande medida, em decorrência das inovações introduzidas pelas empresas montadoras, suas principais clientes que exercem grande pressão sobre os fornecedores, sobretudo na fixação dos preços e as especificações técnicas, de forma a garantir um controle mais sistêmico do processo produtivo ao longo da cadeia (PREVITALLI, 2000).

\section{3 - Método}

A pesquisa de campo, tendo sido realizada por meio de estudos de caso, utilizou-se de um método qualitativo, de pesquisa descritiva (ou exploratória).

Segundo LAZZARINI (1997), os métodos denominados qualitativos caracterizam-se por um foco maior na compreensão dos fatos do que propriamente na sua mensuração. Ele é empregado, segundo RICHARDSON (1985), em casos onde a riqueza dos detalhes é mais relevante do que as informações quantitativas.

A técnica de obtenção de dados empreendida foi a entrevista, que segundo SELLTIZ et al (1967:273) apud GIL (1999), “é bastante adequada para a obtenção de informações acerca do que as pessoas sabem, crêem, esperam, sentem ou desejam, pretendem fazer, fazem ou fizeram, bem como acerca das suas explicações ou razões a respeito das coisas precedentes". Com este intuito, foram conduzidas entrevistas semi-estruturadas, de cerca de uma hora cada, em duas montadoras de motores para automóveis e em dois de seus fornecedores com a utilização de um roteiro formulado a partir da revisão da literatura.

Nas empresas, as pessoas entrevistadas serão preferencialmente aquelas ligadas à tecnologia de produtos, processos e gestão, ou seja, diretores ligados à área tecnológica, diretores industriais e gerentes de produção.

O número de entrevistas variou conforme a empresa. As entrevistas não puderam ser gravadas devido, em alguns casos, às regras das empresas e, em outros, por preferência dos entrevistados. Desse modo as informações obtidas foram apenas anotadas no decorrer das entrevistas. 


\section{4 - Estudos de Caso}

Os estudos de caso foram realizados em três montadoras de motores para automóveis do setor automobilístico brasileiro, conforme mostra a tabela a seguir:

\begin{tabular}{|c|c|c|c|}
\hline & Montadora de Motores "A" & Montadora de Motores “B” & Montadora de Motores "C" \\
\hline Principais clientes & A montadora de automóveis. & $\begin{array}{c}\text { As unidades montadoras de } \\
\text { automóveis. }\end{array}$ & $\begin{array}{c}\text { As unidades montadoras } \\
\text { de } \\
\text { automóveis. }\end{array}$ \\
\hline Principais Produtos & $\begin{array}{l}\text { Motores para automóveis } \\
\text { (motores } 1.0 \text { a } 1.6 \\
\text { envolvendo uma grande } \\
\text { diversidade de produtos). }\end{array}$ & $\begin{array}{c}\text { Motores para automóveis } \\
\text { (motores } 1.0 \text { a } 1.8 \text { e também } \\
\text { motores } 2.0 \text { a } 2.4 \text { ). }\end{array}$ & $\begin{array}{l}\text { Motores para automóveis } \\
\quad \text { (motores } 1.0 \text { a } 1.8 \\
\text { envolvendo uma grande } \\
\text { diversidade de produtos). }\end{array}$ \\
\hline $\begin{array}{l}\text { Diversidade de Produtos } \\
\text { nos últimos anos }\end{array}$ & Aumentou. & Aumentou. & $\begin{array}{l}\text { Aumentou. Em alguns } \\
\text { casos, os novos motores } \\
\text { substituíram motores } \\
\text { existentes. }\end{array}$ \\
\hline $\begin{array}{c}\text { Projetos Recentes em que } \\
\text { as montadoras estão } \\
\text { trabalhando }\end{array}$ & $\begin{array}{c}\text { * adequação de novas } \\
\text { emissões de poluentes de } \\
\text { motores; } \\
\text { * motores a gás; } \\
\text { * motores para um carro } \\
\text { queserá exportado; } \\
\text { * adequação de transmissões } \\
\text { a novos tipos de motores. }\end{array}$ & $\begin{array}{c}\text { A empresa não revelou } \\
\text { quais são os projetos atuais. }\end{array}$ & $\begin{array}{l}\text { A empresa não revelou } \\
\text { quais são os projetos } \\
\text { atuais, mas informou que } \\
\text { há um grande numero de } \\
\text { projetos. }\end{array}$ \\
\hline \multirow[t]{2}{*}{$\begin{array}{l}\text { Setor responsável pelas } \\
\text { atividades de } \\
\text { Desenvolvimento de } \\
\text { Produtos } \\
\text { (valores aproximados) }\end{array}$} & $\begin{array}{c}\text { Existe um total de } 680 \\
\text { pessoas atuando na } \\
\text { engenharia de produto no } \\
\text { Brasil, e cerca de } 550 \text { deles } \\
\text { são engenheiros. }\end{array}$ & $\begin{array}{c}\text { Existe um total de } 900 \\
\text { pessoas atuando na } \\
\text { engenharia de produto no } \\
\text { Brasil, e cerca de } 430 \text { deles } \\
\text { são engenheiros. }\end{array}$ & $\begin{array}{c}\text { Existe um total de } 470 \\
\text { pessoas atuando na } \\
\text { engenharia de produto no } \\
\text { Brasil. }\end{array}$ \\
\hline & $\begin{array}{c}\text { No segmento de motores: } \\
180 \text { pessoas } \\
\text { Curso superior: } 180 \\
\text { Pós-Graduação: } 108 \\
\text { Técnicos: grande parte fez } \\
\text { curso técnico antes de cursar } \\
\text { engenharia. } \\
\text { * Contrata projetistas } \\
\text { temporários. } \\
\text { * Bastante interação com a } \\
\text { matriz (exterior). } \\
\text { * Alguns engenheiros estão } \\
\text { fazendo estágio na matriz } \\
\text { (exterior). } \\
\Rightarrow \text { O n }{ }^{\circ} \text { total diminuiu nos } \\
\text { últimos anos, quando } \\
\text { ocorreu uma redução do n }{ }^{\circ} \\
\text { total de funcionários da } \\
\text { empresa. }\end{array}$ & $\begin{array}{c}\text { No segmento de motores: } \\
190 \text { pessoas } \\
\text { Curso superior: } 100 \\
\text { Pós-Graduação: } 20 \\
\text { Técnicos: } 13 \\
\text { Outros: } 62 \\
\text { * Contrata projetistas } \\
\text { temporários. } \\
\text { * Bastante interação com a } \\
\text { matriz (exterior). } \\
\Rightarrow \text { O n total de pessoas do } \\
\text { setor aumentou em } 50 \text { nos } \\
\text { últimos anos. }\end{array}$ & $\begin{array}{c}\text { No segmento de motores: } \\
163 \text { pessoas } \\
\text { Curso superior: } 130 \\
\text { Pós-Graduação: a maioria } \\
\text { dos engenheiros. } \\
\text { * Contrata projetistas } \\
\text { temporários. } \\
\text { * Bastante interação com o } \\
\text { departamento de } \\
\text { Desenvolvimento da } \\
\text { matriz } \\
\text { (exterior). } \\
\text { * Alguns engenheiros } \\
\text { estão } \\
\text { fazendo estágio na matriz } \\
\text { (exterior). } \\
\Rightarrow \text { O no total de pessoas do } \\
\text { setor aumentou nos } \\
\text { últimos anos. }\end{array}$ \\
\hline
\end{tabular}




\begin{tabular}{|c|c|c|c|}
\hline $\begin{array}{c}\text { Autonomia } \\
\text { Tecnológica em relação } \\
\text { à matriz }\end{array}$ & $\begin{array}{c}\text { * Possui autonomia para } \\
\text { desenvolver motores a partir } \\
\text { de motores existentes. } \\
\text { Destacam-se os } \\
\frac{\text { desenvolvimentos locais: }}{* \text { motores a álcool; }} \\
\text { * motores } 1.0 \text { inexplorados } \\
\text { pela concorrência; } \\
\text { * motores } 1.0 \text { com } 16 \mathrm{~V} \text { para } \\
\text { exportação; } \\
* \text { motor } 1.4 \text { para um carro } \\
\text { utilizado na Europa; } \\
* \text { motores bi-combustível. } \\
\Rightarrow \text { Autonomia para inovações } \\
\text { em processos. }\end{array}$ & $\begin{array}{l}\text { * Possui autonomia para } \\
\text { desenvolver motores a } \\
\text { partir de motores } \\
\text { existentes. } \\
\text { Destacam-se os } \\
\frac{\text { desenvolvimentos locais: }}{* \text { transmissão; }} \\
\text { * motores a álcool; } \\
\text { * materiais visando } \\
\text { resistência à corrosão; } \\
\text { * motores } 1.0 ; \\
\text { * motores bi-combustível. } \\
\\
\Rightarrow \text { Autonomia para } \\
\text { inovações em processos. }\end{array}$ & $\begin{array}{c}\text { * Possui autonomia para } \\
\text { desenvolver motores a } \\
\text { partir de motores } \\
\text { existentes. } \\
\text { Destacam-se os } \\
\text { desenvolvimentos locais: } \\
\text { * precursora do motor a } \\
\text { álcool; } \\
\text { * materiais visando } \\
\text { resistência à corrosão; } \\
\text { * as linhas de motores } \\
\text { fabricadas no Brasil } \\
\text { foram desenvolvidas na } \\
\text { matriz com a } \\
\text { participação de } \\
\text { engenheiros brasileiros. } \\
\text { * motores } \\
\text { bicombustível. } \\
\Rightarrow \text { Autonomia para } \\
\text { inovações em processos. }\end{array}$ \\
\hline Estratégias de DP & $\begin{array}{c}\text { DP para mercados } \\
\text { emergentes: } \\
\text { motor de baixa cilindrada e } \\
\text { maior potência; motor com } \\
\text { sistema de combustível } \\
\text { flexível. }\end{array}$ & $\begin{array}{l}\text { DP para mercados } \\
\text { emergentes: motor de baixa } \\
\text { cilindrada e maior potência; } \\
\text { motor com sistema de } \\
\text { combustível flexível. }\end{array}$ & $\begin{array}{c}\text { DP para mercados } \\
\text { emergentes: motor com } \\
\text { sistema de } \\
\text { combustível flexível. } \\
\text { A meta é ter autonomia em } \\
\text { DP para mercados } \\
\text { emergentes. }\end{array}$ \\
\hline $\begin{array}{l}\text { Componentes } \\
\text { terceirizados } \\
\text { (outsourcing) }\end{array}$ & $\begin{array}{l}\text { Desde o início da produção, } \\
\text { possui alto nível de } \\
\text { outsourcing, quando } \\
\text { comparada às demais } \\
\text { montadoras. } \\
\text { Terceiriza componentes que } \\
\text { não são considerados } \\
\text { tecnologicamenteestratégicos } \\
\text { para a empresa. } \\
\text { Faz a usinagem internamente } \\
\text { e terceiriza a fundição. }\end{array}$ & $\begin{array}{c}\text { Realizou outsourcing de } \\
\text { grande parte de seus } \\
\text { componentes recentemente. } \\
\text { Terceiriza componentes } \\
\text { que não são considerados } \\
\text { tecnologicamente } \\
\text { estratégicos para a empresa. } \\
\text { Terceirizou a usinagem e } \\
\text { tem a intenção de terceirizar } \\
\text { a fundição. }\end{array}$ & $\begin{array}{c}\text { Terceiriza componentes } \\
\text { que não são considerados } \\
\text { tecnologicamente } \\
\text { estratégicos para a } \\
\text { empresa. } \\
\text { Faz internamente a } \\
\text { usinagem do bloco motor, } \\
\text { virabrequim e cabeçote. }\end{array}$ \\
\hline $\begin{array}{c}\text { Relações com centro de } \\
\text { pesquisa ou } \\
\text { universidades para } \\
\text { desenvolvimento de } \\
\text { projetos ou aquisição de } \\
\text { tecnologia }\end{array}$ & $\begin{array}{l}\text { Apenas realiza testes em } \\
\text { dinamômetros em parceria } \\
\text { com uma universidade. }\end{array}$ & $\begin{array}{l}\text { Apenas realiza testes em } \\
\text { dinamômetros em parceria } \\
\text { com uma universidade. }\end{array}$ & $\begin{array}{c}\text { Realiza testes em } \\
\text { dinamômetros em parce } \\
\text { com uma universidade e } \\
\text { possui relações com uma } \\
\text { universidade federal. }\end{array}$ \\
\hline $\begin{array}{c}\text { Desenvolvimento em } \\
\text { conjunto de produtos } \\
\text { (co-design) }\end{array}$ & $\begin{array}{c}\text { Realiza para alguns } \\
\text { componentes: } \\
\text { * Sistema Blowby } \\
\text { (desenvolvido com um } \\
\text { fornecedor); } \\
\text { * motor a gás (desenvolvido } \\
\text { com uma empresa } \\
\text { especializada); } \\
\text { * motor bi-combustível } \\
\text { (com fornecedores). }\end{array}$ & $\begin{array}{c}\text { Realiza para alguns } \\
\text { componentes: } \\
* \text { transmissão } \\
\text { (desenvolvida em conjunto } \\
\text { com um fornecedor); } \\
\text { * motor bi-combustível } \\
\text { (desenvolvido com } \\
\text { fornecedores). }\end{array}$ & $\begin{array}{l}\text { Realiza para alguns } \\
\text { componentes: } \\
\text { * sistemas de injeção } \\
\text { (desenvolvidos } \\
\text { comfornecedores); } \\
\text { * motor bi-combustível } \\
\text { (desenvolvido com } \\
\text { fornecedores). }\end{array}$ \\
\hline
\end{tabular}




\begin{tabular}{|c|c|c|c|}
\hline $\begin{array}{l}\text { Treinamento de } \\
\text { funcionários }\end{array}$ & $\begin{array}{l}\text { No início da produção da } \\
\text { fábrica foram feitos } \\
\text { investimentos intensivos em } \\
\text { treinamento de funcionários. } \\
\text { A empresa continua } \\
\text { investindo em treinamento de } \\
\text { funcionários, especialmente } \\
\text { para a qualidade. }\end{array}$ & $\begin{array}{l}\text { Embora os investimentos } \\
\text { em treinamentos estejam } \\
\text { reduzindo, existem } \\
\text { treinamentos voltados para } \\
\text { melhorias de produtos e } \\
\text { processos, conforme as } \\
\text { necessidades da empresa. }\end{array}$ & $\begin{array}{c}\text { Atualmente os } \\
\text { treinamentos } \\
\text { estão mais focados, ou } \\
\text { seja, mais direcionados } \\
\text { às necessidades. A carga } \\
\text { horária aumentou e } \\
\text { existem mais } \\
\text { funcionários com aptidão } \\
\text { para fazer treinamentos. }\end{array}$ \\
\hline Exploração de tecnologias & $\begin{array}{c}\text { Não realiza a exploração } \\
\text { comercial de tecnologias } \\
\text { dominadas (não compra ou } \\
\text { licencia tecnologias de } \\
\text { produto e processos } \\
\text { desenvolvidas por outras } \\
\text { empresas para } \\
\text { incorporar em seus próprios } \\
\text { produtos e processos). }\end{array}$ & $\begin{array}{l}\text { Não realiza a exploração } \\
\text { comercial de tecnologias } \\
\text { dominadas (não compra ou } \\
\text { licencia tecnologias de } \\
\text { produto e processos } \\
\text { desenvolvidas por outras } \\
\text { empresas para incorporar } \\
\text { em seus próprios produtos } \\
\text { e processos). }\end{array}$ & $\begin{array}{l}\text { Não realiza a exploração } \\
\text { comercial de tecnologias } \\
\text { dominadas (não compra ou } \\
\text { licencia tecnologias de } \\
\text { produto } \\
\text { e processos desenvolvidas } \\
\text { por outras empresas para } \\
\text { incorporar em seus } \\
\text { próprios produtos e } \\
\text { processos). }\end{array}$ \\
\hline Proteção de Tecnologia & $\begin{array}{l}\text { Fornecedores assinam } \\
\text { contratos de } \\
\text { confidencialidade. }\end{array}$ & $\begin{array}{c}\text { Fornecedores assinam } \\
\text { contratos de } \\
\text { confidencialidade. }\end{array}$ & $\begin{array}{l}\text { Fornecedores, e em } \\
\text { alguns casos clientes, } \\
\text { assinam contratos de } \\
\text { confidencialidade. }\end{array}$ \\
\hline
\end{tabular}

\section{5 - Análise dos Estudos de Caso}

As três empresas estudadas apresentam setores de atividades de Desenvolvimento de Produtos estruturados, integrados com a matriz no exterior e voltados para o aumento da diversidade de produtos.

Apesar de tais semelhanças, enquanto a empresa "A" reduziu o número total de pessoas envolvidas com desenvolvimento nos últimos anos, quando houve uma redução de $20 \%$ do total de seus funcionários, na empresa "B" esta estrutura aumentou em aproximadamente $35 \%$, devido o aumento do número de projetos em andamento e da autonomia da empresa em relação a matriz no exterior; na empresa "C" a estrutura também aumentou com o aumento do número de projetos.

O número de pessoas envolvidas com desenvolvimento tecnológico nas montadoras de motores estudadas tornou-se muito próximo após as mudanças ocorridas.

As três empresas apresentam autonomia em relação as suas respectivas matrizes no exterior, com a realização de desenvolvimentos locais importantes, especialmente em motores de baixas cilindradas e de combustíveis flexíveis.

De modo geral, as três empresas possuem autonomia local para desenvolver novos produtos a partir de outros já existentes (possivelmente desenvolvidos em algum momento pela matriz no exterior), além de desenvolverem inovações de processos. Consideram bastante importante que haja 
troca de informações entre os departamentos e entre os funcionários, além da troca de informações com clientes e fornecedores.

Quando as montadoras de motores desenvolvem um novo produto, os fornecedores imediatos recebem as especificações necessárias para desenvolver componentes que se adaptem ao novo motor; do mesmo modo, os fornecedores imediatos passam para alguns de seus fornecedores (os fornecedores de segundo nível das montadoras) especificações para a produção de componentes voltados para os novos componentes.

As relações observadas neste conjunto de empresas caracterizam-se por relações de fornecimento onde cada empresa domina a tecnologia necessária para a produção de seus componentes. Entretanto, existem casos em que o fornecedor, tendo capacidade tecnológica limitada, a montadora transfere a ele o design do produto, restando a este as adaptações no seu processo de produção.

Uma outra possibilidade é a de desenvolvimento de produtos em conjunto (co-design). Entendemos como co-design as relações onde firmas cooperam, com base em suas capacidades tecnológicas.

Os estudos de caso demonstram que as três montadoras realizam co-design, para componentes diferenciados, exceto o motor bi-combustível que as três o fazem com fornecedores comuns.

Embora as três empresas terceirizem parte significativa de seus componentes, preocupam-se em manter o domínio de tecnologias consideradas estratégicas para seus produtos (parte central do motor). Uma exceção, no caso das montadoras estudadas, refere-se a tecnologia de componentes eletrônicos, que apesar de representarem componentes de grande importância para motores, a tecnologia é de domínio dos fornecedores.

As três montadoras se preocupam constantemente em analisar os produtos dos concorrentes e em manter contato com a matriz no que diz respeito a Desenvolvimento de Produtos.

Verifica-se nas empresas grande proximidade entre as áreas de Engenharia e de Produção, dada a preocupação no sentido de que tecnologias sejam mais facilmente aplicadas na produção. $\mathrm{Na}$ empresa "A" todos projetos são implementados através de grupos multifuncionais de funcionários.

As três investem em treinamento de funcionários e, com exceção da empresa "B" onde os investimentos em treinamentos diminuíram, as empresas " $\mathrm{A}$ " e "C $\mathrm{C}$ " têm a meta de manter ou aumentar as horas de treinamento por funcionários em relação ao ano anterior.

Nenhuma das empresas estudadas realiza a exploração comercial de tecnologias dominadas e as três fazem contratos de confidencialidade com fornecedores para que estes não passem tecnologia da empresa para a concorrência. 


\title{
6- Considerações Finais
}

Conforme já mencionado, algumas pesquisas realizadas no setor automobilístico (junto às montadoras de automóveis) indicam que as matrizes das diversas empresas possuem diferentes estratégias de divisão e localização de atividades de desenvolvimento tecnológico e de projeto de produto com relação às suas subsidiárias brasileiras.

As três montadoras de motores estudadas iniciaram os investimentos em atividades de engenharia de produto no Brasil em períodos diferentes, sendo a empresa "A" a pioneira delas, e foram, com o passar do tempo, orientando e estruturando tais atividades em função dos elementos da competitividade local. Isso pode justificar algumas das semelhanças encontradas entre as empresas estudadas.

Ao comparar a autonomia concedida à estrutura de desenvolvimento tecnológico de cada uma destas subsidiárias brasileiras, constatou-se que as três apresentam autonomia crescente em relação as suas respectivas matrizes no exterior para desenvolverem produtos a partir de outros já existentes. As três possuem autonomia para desenvolverem inovações em processos de produção. A montadora "C" tem como meta atingir autonomia em DP para mercados emergentes.

Nenhuma dessas empresas possui fornecedores exclusivos, e, apesar de nenhum fornecedor ter sido estudado, questões levantadas nos estudos de caso realizados nas montadoras indicam que as três empresas estudadas realizam esforços tecnológicos em conjunto com fornecedores, em determinados casos.

Quando as montadoras desenvolvem um novo produto, passam especificações para os fornecedores desenvolverem componentes de acordo com esse novo motor. Há também casos em que as montadoras cedem o design dos componentes para os fornecedores produzi-los, ou ainda, há casos que realizam co-design.

Trabalhos futuros poderiam ser realizados, onde uma comparação entre todas as montadoras de motores instaladas no Brasil fosse realizada e maiores variações poderiam surgir.

\begin{abstract}
In Brazilian automotive industry, the Product Development activities have been influenced by phenomena specific to the national scenario (like the low-displacement and bi-fuelled engines), by changes on supply chains resulting from the investments made by new automakers in order to set up new assembly plants in the country, as well as the consolidation and denationalization of the autoparts. This work aims at comparing the degree of technological autonomy granted to the Product Development structures of three car-engine manufacturers, as well as the technological effort that they make together with their suppliers. The results of this study demonstrate that those companies show increasing autonomy from their corresponding headquarters overseas in the activity of developing products based on pre-existent ones, besides autonomy to carry out innovations in production processes. When the car-engine manufacturer develops a new product, it demands innovations from its supply chain.
\end{abstract}

Key-words: Product Development, Car Engines, Brazilian Automotive Industry. 


\section{Referências}

CONSONI, F.L. Da tropicalização ao projeto de veículos: um estudo das competências em desenvolvimento de produtos nas montadoras de automóveis no Brasil. 2004. Tese (Doutorado em Política Científica e Tecnológica) Instituto de Geociências -Universidade Estadual de Campinas. 269 p. Campinas -SP, 2004.

DIAS, A.V.C. Produto Mundial, Engenharia Brasileira: Integração de Subsidiárias no Desenvolvimento de Produtos Globais na Industria Automobilística. 2003. Tese (Doutorado em Engenharia de produção) - Escola Politécnica da Universidade de São Paulo. São Paulo, 2003.

DIAS, A.V.C.; SALERNO, M.S. Construindo competitividade por meio da organização do desenvolvimento de produtos globais: proposições a partir de estudos de caso no setor automotivo brasileiro. In: ENEGEP, 23. 2003. Ouro Preto, MG, Brasil. Anais do XXIII ENEGEP. CDRom.

GIL, A. C. Métodos e Técnicas de Pesquisa Social. 5a Edição, Ed. Atlas, 1999.

GOMES, R. O papel das subsidiárias e a internacionalização das atividades tecnológicas pelas empresas transnacionais (ETNs). Revista Gestão \& Produção. V. 10, n.3, pp. 267-282, dezembro 2003.

HUMPHREY, J.; SALERNO, M.S. Globalization and assembler-supplier relations: Brazil and India. In: HUMPHREY, J.; LECLER, Y.; SALERNO, M. S. (edts) Global Strategies and Local Realitie: The Auto Industry in Emerging Markets. (in association with GERPISA- Resseau International) Macmillan Press Ltd, 2000.

LAZZARINI, S. G. Estudos de caso: aplicações e limites do método. In: FARINA, E. Estudos de caso em agribusiness. São Paulo: Pioneira, 1997.

POSTHUMA, A.C. Autopeças na encruzilhada: modernização desarticulada e desnacionalização. In: ARBIX, G.; ZILBOVICIUS, M. (orgs.). De JK a FHC: a reinvenção dos carros. São Paulo: Scritta, 1997.

PREVITALLI, F. S. Reestruturação produtiva e novas relações interfirmas na cadeia automobilística nos anos 90. Produto \& Produção, v.4, n.3, p.62-76, out., 2000.

QUADROS Carvalho, R. et al. Globalização e reestruturação da cadeia produtiva na indústria automotiva: qual é o papel do Mercosul? Campinas: Convênio IPEA-DPCT/IG/UNICAMP- FUNCAMP, 2000. Relatório Final.

RACHID, A. Relações entre grandes e pequenas empresas de autopeças - um estudo sobre a difusão de práticas de organização da produção. 2000. Tese (Doutorado em Engenharia de Produção) - Universidade Estadual de Campinas. Campinas - SP, 2000.

RICHARDSON, R.J. Pesquisa Social: método e técnicas. São Paulo, Atlas, 1985.

RIEG, D.L.; ALVES FILHO, A.G. Esforço Tecnológico e Desempenho Inovador das Empresas do Setor MédicoHospitalares localizadas em São Carlos-SP. Revista Gestão \& Produção. V.10, n.3. pp. 293-310, 2003.

ROZENFELD, H; CALPADO AMARAL, D.; TOLEDO, A.C.; SILVA, S.L.; ALLIPRANDINI, D.H.; SCALICE, R.K. Gestão de Desenvolvimento de Produtos - Uma referência para a melhoria do processo. Editora Saraiva, 2006.

SALERNO, M.S. et al. Mapeamento da nova configuração da cadeia automotiva brasileira. Pesquisa realizada junto ao BNDES. Escola Politécnica da Universidade de São Paulo, Departamento de Engenharia de Produção. Relatório Final, outubro, 2001.

\section{Dados completos do primeiro autor:}

Nome completo: Aline Lamon Cerra

Filiação institucional: Universidade Federal de São Carlos

Função ou cargo ocupado: Professora 
Endereço completo para correspondência (bairro, cidade, estado, país e CEP): Rodovia Washington Luis

(SP-310), Km 235. CEP: 13565-905 - Sao Carlos- SP - Brasil

Telefones para contato: (16) 33518236

e-mail:

Recebido para publicação em: 12/11/2005

Aceito para publicação em: 06/01/2006 